Gut, 1986, 27, 1138-1142

\title{
Dietary salt and gastric ulcer
}

\author{
AMNON SONNENBERG \\ From the Department of Medicine, Division of Gastroenterology, Beth Israel Hospital, Harvard Medical \\ School, Boston, USA
}

SUMmary Statistically significant linear correlations between geographic variations in salt consumption and mortality from gastric, but not duodenal ulcer, are reported. It is suggested that dietary consumption of salt is a risk factor in mortality from gastric ulcer.

\begin{abstract}
Although it has been speculated that dietary factors play a role in the aetiology of gastric ulcer disease, firm evidence to this effect is lacking.' Japan is known to have a high incidence of gastric ulcer disease, ${ }^{2}{ }^{3}$ and a conspicuous fact about Japanese diet is its high content of salted food. ${ }^{+}$Furthermore, salt has been found to induce gastritis in animals. ${ }^{5}$ In the present paper, the possibility was examined that geographic variations in mortality from gastric ulcer might be related to those of salt intake. Because mortality from cerebrovascular diseases is known to be related to hypertension and salt consumption. additional evidence for a possible link between salt consumption and gastric ulceration was sought by comparing the geographic and temporal variations of mortality from gastric ulcer and cerebrovascular diseases.
\end{abstract}

\section{Methods}

\section{SALT CONSUMPTION}

Statistics concerning the consumption of food grade salt from different countries were supplied by the Verein Deutsche Salzindustrie in Bonn, FRG, the Comité Européen d'Étude du Sel in Paris, France, and the Salt Institute in Alexandria, Virginia, USA. The figures shown in the Table for New Zealand. Canada, the United States, and Japan pertain to the period of 1978-80, while figures for the other countries relate to the period of 1971-1975. The average annual consumption of each country was divided by the average population for the same period to calculate the per capita consumption. Food grade salt makes up only a small fraction $(5-8 \%)$ of total salt production, ${ }^{67}$ and most of it is

Address for correypendence: A Sonnenherg. MID). (iastrocenterologe D)ivision. Beth Isract Hospitil. 330 Broskline Avenue. Boston. MA 12215. ISA.

Received for publication o February 1986. used in food processing. Much is lost during the process of food preparation, due to food degradation, or remains in the brine and does not enter the human body. Therefore, the per capita consumption calculated from the total consumption of table salt exceeds the actual dietary load by a factor of 2-3.

To validate the correlations obtained from the data of total national consumption of food grade salt, additional sources of salt consumption were sought. Despite its limitations, the 24 hour measurement of urinary sodium output over several days is presently considered to be the most reliable and reproducible criterion, but for political reasons it is not applicable to large populations. For the present analysis the results of different studies compiled by Joossens et al supplemented by two other reports have been used.

The mortality from cerebrovascular diseases, gastric and duodenal ulcer was analysed for countries where either the consumption of food grade salt or the urinary excretion of sodium chloride was known (Table). The mortality data from these 19 countries were made available by the National Departments of Health or the National Statistical Offices. The terms 'stroke' or 'cerebrovascular diseases' were used for the sum of all deaths from cerebrovascular diseases grouped under the ICD codes $430-438$ in the detailed list of the 8 th revision. The average agespecific death rates of the period 1971-1975 were calculated for each country, and in case of New Zealand, Canada, United States, and Japan also the averages of $1978-80$. The death rates were adjusted to the age distribution of the population of England and Wales in 1971 by the method of direct standardisation. ${ }^{10}$

For the analysis of the temporal changes of cerebrovascular diseases, gastric, and duodenal ulcer, the Vital Statistics of the United States from 1921 to 1980 were used. ${ }^{11-1.3}$ All deaths resulting 
Table 1 Salt intake and death rates from cerebrovascular diseases (CVD), gastric (GU) and duodenal ulcer (DU)

\begin{tabular}{|c|c|c|c|c|c|c|c|}
\hline Country & & $\begin{array}{l}\text { Average population } \\
1971-5,(.00())\end{array}$ & $(V D)$ & (;U & $D U$ & $\begin{array}{l}\text { Comsump). } \\
\text { of } \mathrm{NaCl} \\
\text { (lot tons) }\end{array}$ & $\begin{array}{l}\text { Urinary } \\
\mathrm{NaC} \text { (g) } \\
\mathrm{g} / \mathrm{day})\end{array}$ \\
\hline United Kingdom & (UK) & 55120 & 168 & $3 \cdot 5$ & $1 \cdot()$ & 300 & - \\
\hline Scotland & $(\mathrm{SCO})$ & 5212 & 212 & $3 \cdot()$ & $5 \cdot()$ & - & $16 \cdot 0$ \\
\hline England & (ENG) & 48378 & 162 & $3 \cdot 6$ & $4 \cdot()$ & - & 9.9 \\
\hline Finland & $(\mathrm{FIN})$ & 4629 & 165 & $3 \cdot 6$ & 1.5 & - & $12 \cdot 2$ \\
\hline Denmark & (DEN) & 5016 & 103 & 4.8 & $2 \cdot 6$ & 62 & - \\
\hline Netherlands & (NET) & 13435 & 119 & $3 \cdot 4$ & $2 \cdot 0$ & 89 & - \\
\hline Belgium & (BEL) & 9756 & 164 & 4.7 & 0.8 & 127 & $12 \cdot 8$ \\
\hline France & (FRA) & 51224 & 145 & 3.7 & $(0.7$ & 369 & - \\
\hline West Germany & (GER) & 61791 & 178 & 4.9 & $2 \cdot 2$ & 347 & $12 \cdot 2$ \\
\hline Austria & (AUS) & 7511 & 188 & 4.8 & 4.4 & +3 & - \\
\hline Switzerland & (SWI) & 6290 & 121 & 3.7 & $2 \cdot 7$ & 60 & - \\
\hline Spain & (SPA) & 34780 & 188 & 5.7 & $2 \cdot 2$ & 503 & - \\
\hline Portugal* & (POR) & $95(16$ & 330 & $7 \cdot 0$ & 4.4 & 198 & $18 \cdot 0$ \\
\hline Greece & (GRE) & 8931 & 161 & $3 \cdot 1$ & $1 \cdot 7$ & 45 & - \\
\hline Italy & (ITA) & 54207 & 161 & $3 \cdot 6$ & 4.5 & 380 & - \\
\hline Australia & (AUL) & 13137 & 188 & $3 \cdot 2$ & $3 \cdot 1$ & - & $10 \cdot 2$ \\
\hline New Zealand & (NEW) & 3128 & 140 & $2 \cdot 6$ & 3.4 & 30 & $10 \cdot 6$ \\
\hline Canada & $(\mathrm{CAN})$ & 23697 & 89 & $1 \cdot 6$ & $1 \cdot 8$ & 106 & - \\
\hline USA $\div$ & (USA) & $2244(1) 3$ & 89 & 1.2 & 1.2 & 965 & 9.7 \\
\hline Japan & (JAP) & 11.54 .31 & 212 & 6.0 & $1 \cdot 1$ & $1+31$ & $18 \cdot 0$ \\
\hline
\end{tabular}

Death rates given as annual average per $100(0) 0$ living population of the period 1971-1975.

"Death rates of gastric and duodenal uleer refer to the average of $1966-1970$.

$\rightarrow$ Salt consumption and death rates refer to the average of 1978-1980.
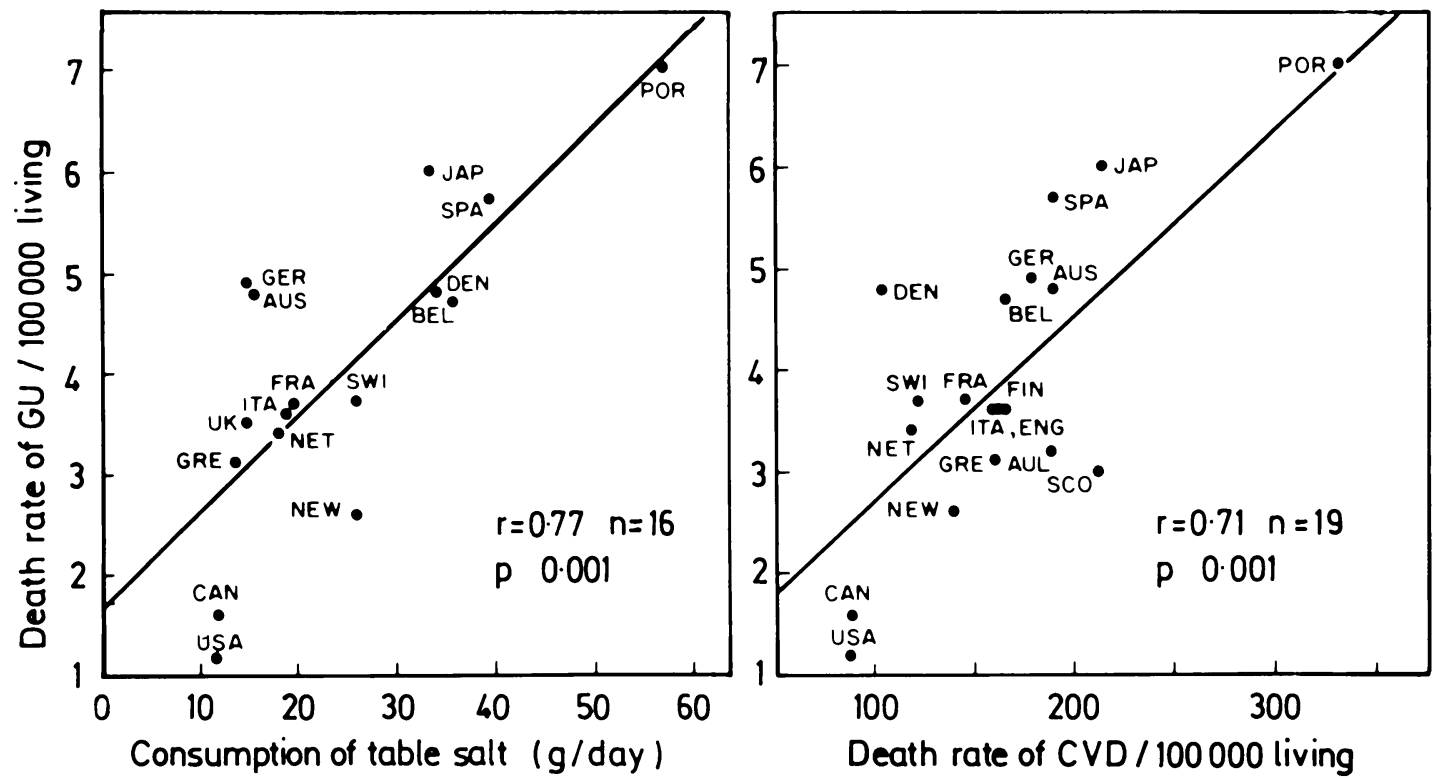

Fig. 1 Correlations of death rates from gastric ulcer $(G U)$ with average daily consumption of table salt and death rates from cerebrovascular diseases (CVD).

from any type of cerebrovascular disease were grouped together. The age- and sex-specific numbers of deaths for each year were related to $100(000)$ male or female US residents of the same age groups and years. The rates for each year were adjusted to the age distribution of the American population of the census in 1980 .

The correlations between the geographic and temporal changes in salt consumption and the death rates from cerebrovascular diseases, gastric and 
duodenal ulcer were tested by least squares linear regression analyses. ${ }^{14}$

\section{Results}

Figure 1 shows a significant linear correlation between the consumption of food grade salt and mortality from gastric ulcer among different countries. The data in the Table show no such significant correlation between the mortality from duodenal ulcer and the consumption of food grade salt $(\mathrm{r}=0.27, \mathrm{n}=16, \mathrm{p}>0.05)$. Mortality from gastric ulcer, but not duodenal ulcer, is significantly correlated to mortality from cerebrovascular diseases (Fig. 1). A significant correlation is also found between the mortality of gastric ulcer and urinary excretion of sodium chloride from 10 countries (Fig. 2). Again, there is no significant correlation between duodenal ulcer and urinary sodium chloride $(\mathrm{r}=0 \cdot 12, \mathrm{n}=10, \mathrm{p}>0.05)$. Calculation of the death rates either for all ages or for persons only between 45 and $75+$ years of age leaves the results of the regression analyses unaffected. The correlations remain significant when tested for men and women separately.

In the United States, the female death rates from cerebrovascular diseases and gastric ulcer run parallel since $1921(\mathrm{r}=0 \cdot 92, \mathrm{n}=60, \mathrm{p}<0 \cdot 001)$. In men, there is a rise in the mortality from gastric ulcer until 1940; after the initial rise, the curves of gastric ulcer and cerebrovascular disease run parallel $(r=0.75$, $\mathrm{n}=60, \mathrm{p}<0 \cdot 001)$. All curves show a smooth peak

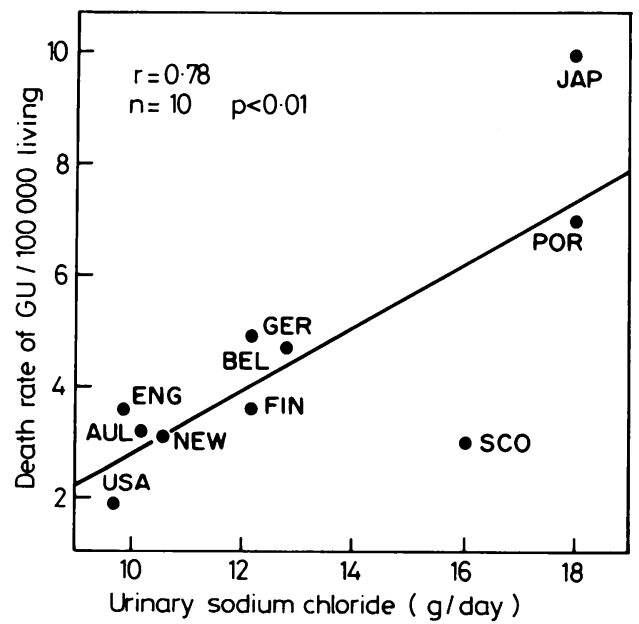

Fig. 2 Correlation of death rates from gastric ulcer $(G U)$ with urinary excretion of sodium chloride. Death rates correspond to the averages of 1971-75. between 1956 and 1965 (Fig. 3). The parallel time course does not concern the mortalities from duodenal ulcer or other benign gastrointestinal diseases. The same kind of similarity in the secular trends of cerebrovascular diseases and gastric ulcer can also be demonstrated for European countries and Japan.

\section{Discussion}

The present analysis shows that there is a significant linear correlation between salt consumption or

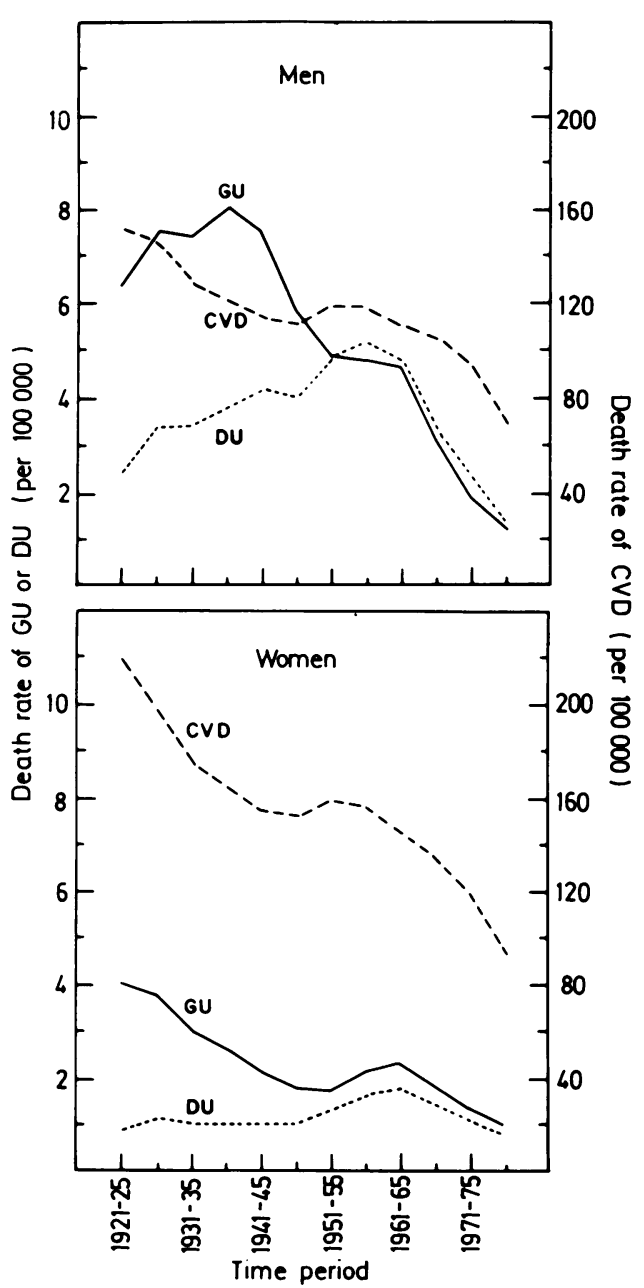

Fig. 3 Comparison of temporal changes in death rates of gastric ulcer $(G U)$, duodenal ulcer $(D U)$, and cerebrovascular disease (CVD) in the United States from 1921 to 1980. Each point is the average of a five-year period. 
urinary sodium chloride excretion and death rates from gastric ulcer in several countries. A validation of this observation is obtained by a significant linear correlation between mortality from gastric ulcer and cerebrovascular diseases. There are additional data suggesting that the occurrence of gastric ulcer may be linked to the amount of dietary salt consumption. One piece of direct evidence is provided by a study by Stemmerman et al who analysed the risk of gastric ulcer among Japanese from Hawaii in a case control study. ${ }^{15}$ The authors found a strong association between salt intake, gastric ulcer, and gastric metaplasia in 133 patients with gastric ulcer as compared with 244 controls. Also, salt was shown to induce gastritis of experimental animals. ${ }^{5}$ The epidemiologic relationship between mortality from gastric cancer and cerebrovascular diseases gives further evidence to the contention that salt consumption can affect the gastric mucosa. ${ }^{16} 17$ The geographic and temporal variations in the amount of urinary salt excretion are significantly correlated to those of mortality from gastric cancer, ${ }^{81618}$ and within countries like Japan and England, regions with a high mortality from gastric cancer also show conspicuously high mortality from cerebrovascular diseases. ${ }^{5} 18$ During the last $20-30$ years mortality from both diseases has declined in a strikingly parallel manner in most countries. ${ }^{816} 19$

The presently described relationship between the occurrence of gastric ulcer and salt consumption may be important in our understanding of the aetiology of gastric ulcer disease. The geographic distribution of gastric ulcer between Western countries and India and Africa, ${ }^{2021}$ for instance, might be related to different grades of salt consumption. The marked temporal variations displayed by the incidence of gastric ulcer in Europe could have been caused by the peculiar history of salt consumption. Gastric ulcer used to be a rare disease in Europe before the onset of the 19th century. ${ }^{22}$ The incidence of gastric ulcer rose steadily during the 19th century and reached a peak in the generation born at the turn of the 20th century. ${ }^{2324}$ During the past decades the frequency of gastric ulcer has again declined. ${ }^{2+26}$ This rise and fall of gastric ulcer is paralleled by a rise and fall in the dietary salt consumption. In Europe, salt was a precious and highly taxed commodity throughout the Middle Ages and the Renaissance. ${ }^{7}{ }^{27}$ Only after the French revolution were the high state taxes on salt abolished or markedly reduced, and only since then did salt become available to all sections of the population. Since the First World War, cooling as a means of preserving food has begun to replace salting, and this has led to a steady decline in salt consumption over the years. ${ }^{18}$ This reduction in dietary consump- tion of salt may form the basis for the parallel decline in mortality from gastric ulcer and cerebrovascular diseases as shown in Figure 3.

Data on salt consumption were kindly provided by Dr Gerhard Kinzel from the Verein Deutsche Salzindustrie in Bonn, FRG, Bernard Moinier, Secretary General of the Comité Européen d'Étude du Sel In Paris, and William E Dickinson, President of the Salt Institute in Alexandria, VA. This study was supported by grant no. So 172/1-1 from the Deutsche Forschungsgemeinschaft.

\section{References}

1 Kurata JH, Haile BM. Epidemiology of peptic ulcer disease. Clin Gastroenterol 1984; 13: 289-307.

2 Ishimori A, Kawamura T. Epidemiology of peptic ulcer disease in Japan. In: Fisher RS, ed. Peptic ulcer disease: an update. New York: Biomedical Information Corporation Publications, 1979: 153-64.

3 Sonnenberg A, Müller $\mathrm{H}$. Cohort and period effects in peptic ulcer mortality from Japan. J Chron Dis 1984; 37: $309-17$

4 Asahina K. Shigiya R, eds. Physiological adaptability and nutritional status of the Japanese. JIBP synthesis: human adapability. Vol 3. Tokyo: University of Tokyo Press, 1975.

5 Sato T, Fukuyama T, Suzuki T et al. Studies of the causation of gastric cancer. 2. The relation between gastric cancer mortality rate and salted food intake in several places in Japan. Bull Inst Publ Health 1959; 8: $187-98$.

6 Dickinson WE. Present situation on salt products and development of various uses in North American salt markets and environmental considerations. In: Cogan AH, Hauber L, eds. Fifth symposium on salt. Vol 2. Cleveland, OH: The Northern Ohio Geological Society, 1980: 421-6.

7 Seidel H, Woller R. Das Geschenk der Erde. Vom Salz zur modernen (hemie. Düsseldorf: Econ Verlag. 1980): 71-6.

8 Joossens JV. Geboers J. Nutrition and gastric cancer. Nutr Cancer 1981: 2: 250(-61.

9 Tuomilehto J, Karppanen H. Tanskanen A. Tikkanen J, Vuroi J. Sodium and potassium excretion in a sample of normotensive and hypertensive persons in eastern Finland. J Epidemiol Comm Health 1980; 34: 174-8.

10) Kahn HA. An introduction to epidemiologic methods. New York: Oxford University Press, 1983: 63-78.

11 Bureau of the Census. Mortality statistics - Annual report, 1921-1936. Washington DC: US Government Printing Office, 1924-1938.

12 Bureau of the Census. Vital statistics of the United States. Mortality Statistics Branch. Vol II. Mortality. part A, 1937-1944. Washington, DC: US Government Printing Office, 1924-1946.

13 Public Health Service. Vital Statistics of the United States. Mortality Statistics Branch. Vol II. Mortality, 
part A, 1945-1980. Washington, DC: US Government Printing Office, 1947-1985.

14 Zar JH. Biostatistical analysis, 2nd ed. Englewood Cliffs NJ: Prentice Hall, 1984: 261-91.

15 Stemmermann G, Haenszel W, Locke F. Epidemiologic pathology of gastric ulcer and gastric carcinoma among Japanese in Hawaii. J Natl Cancer Inst 1977; 58: 13-9.

16 Joossens JV. Stroke, stomach cancer and salt. In: Kesteloot H. Joossens JV, eds. Epidemiology of arterial blood pressure. The Hague: Martinus Nijhoff Publishers, 1980: 489-508.

17 Whelton PK, Goldblatt P. An investigation of the relationship between stomach cancer and cerebrovascular disease. Am J Epidemiol 1982; 115: 418-27.

18 Joossens JV. Dietary salt restriction - The case in favour. In: Robertson JIS, Pickering GW, Caldwell ADS, eds. The therapeutics of hypertension. Royal Society of Medicine Series No 26. London: Academic Press, 1980: 243-250.

19 Tuomilehto J, Geboers J, Joossens JV, Salonen JT, Tanskanen $\mathrm{T}$. Trends in stomach cancer and stroke in
Finland. Comparison to Northwest Europe and USA. Stroke 1984; 15: 823-8.

20 Tovey F. Duodenal ulcer in black populations in Africa south of the Sahara. Gut 1975; 16: 564-76.

21 Tovey F. Peptic ulcer in India and Bangladesh. Gut 1979; 20: 239-47.

22 Jennings D. Perforated peptic ulcer. Changes in ageincidence and sex-distribution during the last 150 years (part 1 and 2). Lancet 1940; 1: 395-8 and 444-7.

23 Susser M, Stein Z. Civilization and peptic ulcer. Lancet 1962; 1: 115-9.

24 Sonnenberg A, Müller H, Pace F. Birth-cohort analysis of peptic ulcer mortality in Europe. J Chron Dis 1984; 38: $309-17$.

25 Coggon D, Lambert P. Langman MJS. 20 years of hospital admissions for peptic ulcer in England and Wales. Lancet 1981; 1: 13(2-4.

26 Vogt TM, Johnson RE. Recent changes in the incidence of duodenal and gastric ulcer. Am J Epidemiol 1980; 111: 713-20.

27 Denton D. The hunger for salt. New York: SpringerVerlag, 1982: 76-90. 
Metabolism and nutrition in liver disease Edited by $\mathrm{E}$ Holm and $\mathrm{H}$ Kasper. (Pp. 402; illustrated; $£ 45 \cdot 00$.) Lancaster: MTP Press, 1985.

Infectious diarrhoea in the young Edited by $\mathrm{S}$ Tzipori. (Pp. 524; illustrated; \$98.50.) Excerpta Medica 1985.

\section{News}

\section{Hopkins Endoscopy Prize}

The Hopkins Prize is offered annually for a paper on any topic relating to endoscopy. Applicants are invited to submit a three page summary of the proposed paper to the Endoscopy Committee of the BSG who will recommend to Council the recipient of the 1987 Award. The recipient will present a 15 minute paper at the Jubilee Meeting in September 1987 and will receive a prize of $£ 100$ and a permanent momento. Applications (four copies) should be submitted to: Surgeon Commander R J Leicester, The Royal Naval Hospital, Haslar, Gosport, Hampshire PO12 2AA. CLOSING DATE FOR ENTRIES: 1 MARCH, 1987.

\section{Emanoel Lee Scholarship Fund}

St Cross College, Oxford is to establish a scholarship to mark Emanoel Lee's contribution to medicine and the College. Those wishing to contribute should apply to Dr S R Porter, Bursar, St Cross College, Oxford.

\section{Trace Elements in Human Health and Disease}

2nd Nordic Symposium, 17-21 August, 1987, Odense University, Odense, Denmark. Information may be obtained from: Trace Elements in Human Health and Disease, Odense Tourist Association, The Town Hall, DK-5000 Odense C, Denmark.

\footnotetext{
Clinical Controversies in Inflammatory Bowel Diseases

An international symposium on the above will be held in Bologna, Italy from 9-11 September, 1987. Further information may be obtained from Mrs Claudia Servisi, SO.GE.PA.COS.p.A, Piazza Costituzione, 5/c, 40128, Bologna, Italy.
}

\section{Correction}

The references were unfortunately omitted from the letter by D'Amato et al (Gut 1986; 27: 1228) and these are printed below.

\section{References}

1 Gomes P, Dubulay C, Smith CL, Holdstock G. Relationship between disease activity indices and colonscopic findings in patients with colonic inflammatory bowel disease. Gut 1986; 27: 92-5.

2 Best WR, Becktel JM. Singleton JW, Kern F. Development of a Crohn's disease activity index. Gastroenterology 1976; 70: 439-44.

3 Harvey RF, Brandshaw JM. A simple index of Crohn's disease activity. Lancet 1980; 1: 514.

4 Truelove SC, Witts LJ. Cortisone in ulcerative colitis. Final report on a therapeutic trial. $\mathrm{Br} \operatorname{Med} J$ 1955; 2: 1041-8.

5 Powell-Tuck J, Day DW, Buck NA, Wadsworth J, Lennard-Jones JE. Correlation between defined sigmoidoscopic appearance and other measures of disease activity in ulcerative colitis. Dig Dis Sci 1982; 27: 533-7.

6 Cooke WT, Prior P. Determining Disease Activity in Inflammatory bowel disease. J Clin Gastroenterol 1984 ; 6: $17-25$.

7 Cello JP. Ulcerative colitis. In: Sleisenger $\mathrm{MH}$. Fordtran JS eds. Gastrointestinal disease. Philadelphia: W B Saunders Co 1983: 1122-68.

A mistake occurred in the paper by A Sonnenberg entitled 'Dietary salt and gastric ulcer' (Gut 1986; 27: 1138-40) on page 1138, 2nd col, 2nd paragraph, five lines up, it should have read '.... reproducible criterion, but for practical reasons it is..... Dr Sonnenberg has also changed his address to Gastroenterology Section, VA Medical Center, $5000 \mathrm{~W}$ National Avenue, Milwaukee, Wisconsin 53295, USA. 